\title{
A FILOSOFIA DA PSICOLOGIA E O "NOVO MÉTODO" FILOSÓFICO NOS ESCRITOS TARDIOS DE WITTGENSTEIN: UMA RELAÇÃO PRÁTICA E NECESSÁRIA
}

\author{
Gilberto Ferreira de Souza ${ }^{1}$
}

Resumo: O objetivo deste artigo é apresentar os temas do "novo método" filosófico e da "Filosofia da Psicologia", nos escritos tardios de Ludwig Wittgenstein, como relacionados prática e necessariamente. Para o proposto, a estratégia expositiva segue a seguinte ordem: analisam-se os pressupostos filosóficos relativamente irrefletidos que determinam a visão que o jovem Wittgenstein tinha do "método correto da Filosofia" e da "Filosofia da Psicologia"; interpreta-se a volta filosófica de 1929 como comprometida em apresentar o rosto ainda informe do "novo método" e retomar criticamente os alvos do TLP, sob essa nova perspectiva metodológica; e considera-se a Filosofia da psicologia de Wittgenstein inserida numa perspectiva diferente da perspectiva da ciência psicológica do fim do século XIX e início do século XX, fundamentada em investigaçóes empíricas. Essas observaçóes constituem propriamente uma prática do "novo método" de apresentaçâo perspícua e se caracteriza como um aspecto-chave e necessário, um filtro, para a compreensão das observaçóes do filósofo em torno da psicologia e de seu objetivo em dissolver os problemas metafísicos ali presentes.

Palavras-chave: Filosofia. Wittgenstein. Filosofia da Psicologia. Método.

Unsere methode ist die Methode der übersichtlich Darstellung. [O nosso método é o método de apresentação perspícua].

(WITTGENSTEIN)

\footnotetext{
${ }^{1}$ Doutor em Filosofia da Linguagem pela Universidade Estadual de Campinas (UNICAMP), Campinas, Sấo Paulo - Brasil. D https://orcid.org/0000-0002-2378-5563 E-mail: gilbertosouza_2005@yahoo. com.br. Possui experiência docente no Ensino Médio, Técnico e Superior, nas áreas de Filosofia, Ética, Ciências Sociais e Metodologia do Trabalho Científico. Atualmente, desenvolve dois projetos de pesquisa: um que se ocupa com a concepção de "novo método" filosófico nos trabalhos tardios de Wittgenstein e sua aplicação aos conceitos psicológicos, e outro que investiga e relaciona o pensamento de Wittgenstein com aspectos atuais da Bioética.
}

http://doi.org/10.1590/0101-3173.2020.v43esp.14.p177

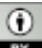

This is an open-access article distributed under the terms of the Creative Commons Attribution License. 


\section{INTRODUÇÁO}

A volta de Wittgenstein para Cambridge, em 1929, estava carregada de compromissos filosóficos, entre os quais o de apresentar o rosto de sua mais recente descoberta, o "novo método" filosófico ainda informe, e o de retomar as reflexões filosóficas sob a perspectiva desse "novo método". As exposições pouco explícitas e enigmáticas que caracterizam essa retomada são fundamentais para todos aqueles que queiram compreender o desenvolvimento posterior do pensamento de Wittgenstein e refletir sobre as relaçóes possíveis das suas observaçóes.

O presente trabalho tem por objetivo apresentar o "novo método" filosófico e a "Filosofia da Psicologia" como temas relacionados prática e necessariamente, nos escritos de Wittgenstein. Para tanto, iniciaremos a nossa reflexão em torno do engajamento de Wittgenstein com os temas e problemas do método e da Filosofia da Psicologia, remetendo-nos ao início de sua carreira filosófica, não porque podemos encontrar lá reflexóes sobre esses assuntos, mas porque encontramos uma série de pressupostos relativamente irrefletidos que gradualmente se tornarão alvos de investigaçóes críticas do próprio Wittgenstein, a partir de 1929, sob a forma de vários temas, entre os quais o método e a Filosofia da Psicologia. Dedicaremos, então, as primeiras observaçóes a alguns pressupostos tractarianos da visão que Wittgenstein teve sobre o "método correto da Filosofia" e sobre a Filosofia da Psicologia.

Em segundo momento, focalizaremos o estado atual do debate em torno do "novo método" na filosofia tardia de Wittgenstein, as interpretaçóes, as perspectivas adotadas e a nossa interpretação sobre a indispensabilidade do "novo método" para a compreensão das observaçôes filosóficas que Wittgenstein empreendeu, desde a sua volta a Cambridge.

Apesar de Wittgenstein jamais ter descrito explicitamente em que consiste o seu "novo método", podemos identificá-lo como uma estratégia de investigação que procura considerar a multiplicidade de perspectivas possíveis na descrição dos usos conceituais e cuja finalidade é libertar o filósofo da hipnose do ideal de método científico que levanta hipóteses e constrói teorias explicativas. Nesse sentido, faremos algumas indicações quanto à sua natureza e características que julgamos ser fundamentais para a presente reflexão.

Por fim, observaremos que a Filosofia da Psicologia de Wittgenstein se insere numa perspectiva diferente da perspectiva da ciência psicológica que se desenvolveu, principalmente, no fim do século XIX e início do século XX, como uma ciência fundamentada em investigaçóes empíricas. E isso se deve ao objetivo do filósofo na obtenção de uma apresentaçâo perspicua dos conceitos 
psicológicos expressos na linguagem, a fim de realizar o propósito de dissolver problemas metafísicos presentes na psicologia.

\section{Alguns pressupostos tractarianos}

Com o término da publicação do Tractatus-Logico-Philosophicus (TLP), Wittgenstein acreditou ter resolvido as questóes cardeais da Filosofia. No prefácio da obra, ele afirma que a verdade dos pensamentos ali comunicados lhe parece intocável e definitiva e que, em sua opiniáo, havia solucionado todos os problemas essenciais da Filosofia.

Quanto à forma de exposição, o TLP é um livro pouco convencional. $\mathrm{O}$ autor elabora um sistema de numeração peculiar que permite indicar cada uma das passagens entre diferentes níveis de argumentos, assim como entre os argumentos em um mesmo nível e seus respectivos "pesos lógicos", no interior do discurso. São sete proposiçóes básicas intercaladas por comentários sistematicamente organizados, mediante uma numeração que convida o leitor a seguir, minuciosamente, a trajetória completa dos diversos movimentos realizados entre os níveis lógicos e entre os argumentos, do início ao final da longa jornada ascendente. Sob esse aspecto, Wittgenstein considerou ter escrito um "bom livro". "Bom", provavelmente, porque não tinha saltos, repetiçóes, lacunas, casos particulares e exemplos específicos, discussóes, comentários longos, diálogos ou explicaçóes.

O projeto tractariano de esclarecimento lógico dos pensamentos é levado a cabo por meio do método de análise lógica das proposições, que seria, segundo o autor, o método propriamente correto:

O método correto da filosofia seria propriamente este: nada dizer, senáo o que se pode dizer; portanto, proposiçôes da ciência natural - portanto, algo que nada tem a ver com a filosofia; e então, sempre que alguém pretendesse dizer algo de metafísico, mostrar-lhe que não conferiu significado a certos sinais em suas proposições. Esse método seria, para ele, insatisfatório - não teria a sensação de que lhe estivéssemos ensinando filosofia; mas esse seria o único rigorosamente correto (MS 204, $53=$ TLP 6.53)².

\footnotetext{
${ }^{2}$ Original:"Die richtige Methode der Philosophie wäre eigentlich die: Nichts zu sagen, als was sich sagen läßt, also Sätze der Naturwissenschaften - also etwas, was mit Philosophie nichts zu tun hat -, und dann immer, wenn ein anderer etwas Metaphysisches sagen wollte, ihm nachzuweisen, daßer gewissen Zeichen in seinen Sätzen keine Bedeutung gegeben hat. Diese Methode wäre für den anderen unbefriedigend - er hätte nicht das Gefühl, daß wir ihn Philosophie lehrten - abers i e wäre die einzig streng richtige." Todas as traduçōes, ao longo do texto, são de minha responsabilidade.
} 
Esse método oferece ao filósofo da lógica um ponto de vista privilegiado sobre o conjunto de operaçóes a priori realizadas com relaçóes internas de sentido. É daí que o filósofo poderá ter a visão correta do mundo (MS 204, $53=$ TLP 6.54$)^{3}$, sendo o livro um instrumento utilizado para essa finalidade e descartado em seguida.

A concepção de Filosofia para Wittgenstein não é a de uma ciência da natureza (MS 204, $15=$ TLP 4.111) ${ }^{4}$ ou de uma teoria $(M S 204,15=$ TLP 4.112) , mas de uma atividade cujo fim é o esclarecimento lógico dos pensamentos anteriormente turvos e indistintos (MS 204, $15=$ TLP 4.111) por causa das confusóes de que ela (a Filosofia) está repleta (MS 204, 9 = TLP 3.324$)^{7}$. A atividade filosófica se caracteriza como reflexão a respeito das relações internas ou de sentido, por contraste com a atividade científica voltada exclusivamente para relações externas, isto é, causais e mecânicas.

Wittgenstein herdou de seus antecessores, Frege e Russell, o antipsicologismo. Como ele afirmou sem rodeios, no TLP, "a psicologia não é mais aparentada com a Filosofia que qualquer outra ciência natural” (MS 204, 16 = TLP 4.1121) ${ }^{8}$. Ele notou que seu estudo da linguagem por sinais não corresponde ao estudo dos processos de pensamento que os filósofos costumavam considerar essencial para a Filosofia da lógica e que deveria tomar cuidado para não se envolver em investigaçôes psicológicas irrelevantes, isto é, inessenciais (MS 204, 16 = TLP 4.1121) ${ }^{9}$. Dessa forma, o tema central do

\footnotetext{
${ }^{3}$ Original:"Meine Sätze erläutern dadurch, daßsie der, welcher mich versteht, am Ende als unsinnig erkennt, wenn er durch sie - auf ihnen - über sie hinausgestiegen ist. (Er mußsozusagen die Leiter wegwerfen, nachdem er auf ihr hinaufgestiegen ist.) Er muß diese Sätze überwinden, dann sieht er die Welt richtig."

${ }^{4}$ Original: "Die Philosophie ist keine der Naturwissenschaften. (Das Wort "Philosophie” muß etwas bedeuten, das über oder unter, aber nicht neben den Naturwissenschaften steht.)"
}

5 Original: "Der Zweck der Philosophie ist die logische Klärung der Gedanken. Die Philosophie ist keine Lehre, sondern eine Tätigkeit. Ein philosophisches Werk besteht wesentlich aus Erläuterungen."

${ }^{6}$ Original: "Die Philosophie ist keine der Naturwissenschaften. (Das Wort Philosophie muß etwas bedeuten, das über oder unter, aber nicht neben den Naturwissenschaften steht.)"

${ }^{7}$ Original: So entstehen leicht die fundamentalsten Verwechslungen (deren die ganze Philosophie voll ist).

8 Original: "Die Psychologie ist der Philosophie nicht verwandter als irgend eine andere Naturwissenschaft. Erkenntnistheorie ist die Philosophie der Psychologie. Entspricht nicht mein Studium der Zeichensprache dem Studium der Denkprozesse, welches die Philosophen für die Philosophie der Logik für so wesentlich hielten? Nur verwickelten sie sich meistens in unwesentliche psychologische Untersuchungen und eine analoge Gefahr gibt es auch bei meiner Methode."

9 Original: "Die Psychologie ist der Philosophie nicht verwandter als irgend eine andere Naturwissenschaft. Erkenntnistheorie ist die Philosophie der Psychologie. Entspricht nicht mein Studium der Zeichensprache dem Studium der Denkprozesse, welches die Philosophen für die Philosophie der Logik für so wesentlich hielten? Nur verwickelten sie sich meistens in unwesentliche psychologische Untersuchungen und eine analoge Gefahr gibt es auch bei meiner Methode." 
TLP - a natureza da proposição e as consequências lógico-metafísicas que fluem de sua natureza essencial - pode e deve ser manuseado sem referência às consideraçóes psicológicas, isto porque seu interesse se centrava nos esclarecimentos exclusivamente lógicos.

Ao excluir as consideraçôes psicológicas, em seu livro, Wittgenstein parece evitar a reflexão sobre conceitos psicológicos. Isso significava concessão a uma série de preconceitos náo examinados ou irrefletidos referentes aos termos "compreender", "ter em mente" e "pensar" como algo menos importante ou inócuo. Como confessará numa observação posterior (MS 142, 78 e TS 227, $69=\mathrm{PU}, \$ 81)^{10}$, isso ainda não estava claro para o jovem filósofo.

A teoria do conhecimento ou epistemologia (Erkenntnistheorie), concebida como Filosofia da Psicologia, seria uma atividade logicamente esclarecedora dos processos de pensamento envolvidos no campo da Filosofia da lógica, mas não uma teoria a respeito do conhecimento. Para ele, a reflexão esclarecedora dos atos de pensamento diz respeito à lógica e náo se deve correr o risco de confundi-la com análise de natureza psicológica, irrelevante para questôes lógicas (MS 204, $16=\mathrm{TLP} 4.1121)^{11}$. Wittgenstein parece reconhecer que há um limite importante a ser observado entre os dois domínios de reflexão, entretanto, que é difícil caracterizá-lo.

Em sua volta para Cambridge, em 1929, Wittgenstein entende que a nova Filosofia deve ocupar-se com a crítica do seu antigo pensamento. No prefácio para as Philosophische Untersuchungen (Investigaçôes Filosóficas - PU), ele assevera:

Há quatro anos, tive a ocasião de ler novamente o meu primeiro livro (o 'Tractatus Logico-Philosophicus') e esclarecer seus pensamentos. Pareceume dever publicar aqueles antigos pensamentos juntos, e os novos, pois estes apenas poderiam receber sua reta iluminação somente pelo confronto

\footnotetext{
${ }^{10}$ Original: "All das kann aber erst dann im rechten Licht erscheinen, wenn man über die Begriffe des Verstehens, Meinens und Denkens größere Klarheit gewonnen hat. Denn dann wird auch klar werden, was uns dazu verleiten kann (und mich verleitet hat) zu denken, daß, wer einen Satz ausspricht und ihn meint, oder versteht, damit einen Kalkül betreibt, nach bestimmten Regeln."

${ }^{11}$ Original: "Die Psychologie ist der Philosophie nicht verwandter als irgend eine andere Naturwissenschaft. Erkenntnistheorie ist die Philosophie der Psychologie. Entspricht nicht mein Studium der Zeichensprache dem Studium der Denkprozesse, welches die Philosophen für die Philosophie der Logik für so wesentlich hielten? Nur verwickelten sie sich meistens in unwesentliche psychologische Untersuchungen und eine analoge Gefahr gibt es auch bei meiner Methode."
} 
com os meus antigos modos de pensar e tendo-os como pano de fundo

(TS 227b, 3 = PU, 81 = PU, Vorwort $)^{12}$.

É no contexto de releitura do TLP que surgem os novos pensamentos e as referências ao "novo método" filosófico.

\section{O “Novo MÉTODo" FILOSÓFICo}

O debate em torno do "novo método" na Filosofia tardia de Wittgenstein ganha mais e mais atenção a cada dia (GILMORE, 1999, p. 47) ${ }^{13}$. Vários trabalhos foram produzidos acerca desse tema e as perspectivas adotadas, que são as mais diversas possíveis, estão, obviamente, dependentes e ancoradas na interpretação tanto do TLP quanto do pensamento geral de Wittgenstein.

Os comentadores Baker e Hacker interpretam o "novo método" de Wittgenstein como um herdeiro direto do Tractatus da noção de "um ponto de vista logicamente correto” presente no TLP, 6.53 (BAKER; HACKER, 2005, p. 532, 544. Ver também: HACKER, 1986, p. 151). Segundo Moreno, o "novo método" de Wittgenstein deve ser entendido por distanciar-se do TLP 6.53 e tendo-o como pano de fundo (MORENO, 2009, p. 141). Parece-nos que as duas interpretaçóes estão em consonância com o desejo de Wittgenstein expresso no prefácio publicado das Philosophische Untersuchungen [Investigaçôes Filosóficas], qual seja, esclarecer seus novos pensamentos pelo confronto com os mais antigos (TS 227b, 3 = PU, Vorwort, citado na nota 12 acima).

Com relação ao pensamento de Wittgenstein, é ponto quase assente entre os comentadores que ele, a partir de 1929, quando está de volta a Cambridge, passa a desenvolver uma nova Filosofia crítica do TLP, inclusive de sua concepção de "método correto da Filosofia". Esse método de análise lógica atuava por demonstraçáo, provas e evidências das ciências naturais e da lógica. A Filosofia era considerada, até então, como uma atividade de elucidação que

\footnotetext{
${ }^{12}$ Original: "Vor vier Jahren aber hatte ich Veranlassung, mein erstes Buch (die 'Logisch-philosophische Abhandlung') wieder zu lesen und seine Gedanken zu erklären. Da schien es mir plötzlich, daß ich jene alten Gedanken und die neuen zusammen veröffentlichen sollte: daß diese nur durch den Gegensatz, und auf dem Hintergrund meiner ältern Denkweise, ihre rechte Beleuchtung erhalten könnten."

${ }_{13}$ Original: "More and more attention is being paid to the importance of Wittgenstein's method in his later philosophy. His later philosophy method has been described as skeptical, as non-skeptical, as idealist, heuristic, deictic, and as therapeutic."
} 
não andava com as suas próprias pernas, o que levaria à conclusão de que o método da Filosofia não tinha sentido, nem se justificava.

No final dos anos 20 e início dos anos 30, Wittgenstein faz várias declaraçôes de que "um novo método havia sido encontrado"14. Trata-se de declaraçóes pouco explícitas e enigmáticas (MOORE, 1955, p. 26) ${ }^{15}$, a respeito das quais, embora sejam fundamentais e confiáveis para qualquer um que queira compreender o desenvolvimento do seu pensamento posterior (STERN; CITRON; ROGERS, 2013, p. 1) ${ }^{16}$, Wittgenstein não facilita a tarefa ${ }^{17}$.

Com relação ao valor do novo método, o próprio Wittgenstein faz várias afirmaçóes, entre elas, a mais famosa encontra-se no parágrafo 122 das PU: ${ }^{14}$ Entre as várias declaraçōes, citamos uma relatada por Moore: "He said that what he was doing was
a 'new subject', and not merely a stage in a 'continuous development'; that there was now, in philosophy,
a 'kink' in the 'development of human thought', comparable to that which occurred when Galileo and his
contemporaries invented dynamics; that a 'new method had been discovered, as had happened when chemistry
was developed out of alchemy'; and that it was now possible for the first time that there should be 'skilful'
philosophers, though of course there had in the past been 'great' philosophers.". Tradução: "Ele disse que o
que ele estava fazendo era um 'novo assunto' ('new subject'), e não apenas uma etapa no 'desenvolvimento
contínuo do pensamento humano', comparável ao que ocorreu quando Galileu e seus contemporâneos
inventaram a dinâmica, que um 'novo método' havia sido descoberto, como tinha acontecido quando a
'química foi desenvolvida a partir da alquimia', e que agora era possivel, pela primeira vez, haver filósofos
'bábeis', embora, naturalmente, não queria dizer, com isso, que não tivemos no passado 'grandes filósofos."
(MOORE, 1955, p. 26). Ver também: KING; LEE (1980, p. 21) e RHEES (1981, p. 125-126).

${ }^{15}$ Segundo as extensas anotaçóes de Moore, Wittgenstein jamais descreve explicitamente em que consiste o seu novo método. Expôs, apenas, algumas indicaçôes quanto à sua natureza (MWL, 1955, p. 27. Ver também, sobre o assunto, em LWL, 1980, p. 22). O presente artigo considera a problematicidade inerente à tradução do conceito übersichtlichen Darstellung e suas variantes, optando pela versão "apresentação perspícua", compreendida como abrangendo os termos "apresentação sinóptica ou panorâmica", "apresentação clara" e "apresentaçáo ordenada". O conceito em questáo, citado ao longo do artigo, está disperso por vários textos do Nachlass de Wittgenstein, como, por exemplo: TS 213, $417=$ BT, $\$ 89,417$, p. 307 ; MS 114 , p. 190 e TS 209, p. $1=$ PB, I, $\$ 2,5$; TS 227b, p. $8=$ PU, $\$ 5$; TS 227b, p. 77 = PU \$92; TS 227b, p. 88 = PU, \$122.

${ }^{16}$ Original: "In 1929, Wittgenstein returned to Cambridge and philosophical writing, criticising his own earlier work and turning his focus to how language is used in ordinary life. These years were a time of transition between his early and his later work, and are of great interest for anyone who wants to understand the development of his thought."

${ }^{17}$ Com relação à leitura de Wittgenstein, Leavis, por exemplo, a denomina como "terrivelmente difícil." LEAVIS, F., 1981. In: RHEES, R. (ed.), 1981, p. 78. Do mesmo modo, para Ramsey, Frege, Fann, Black, Stroll e Ammereller o TLP é "uma das obras clássicas de filosofia mais dificeis de dominar." Cf. RAMSEY, F., 1923, pp. 465-478, p. 465. Cf. FREGE, G., 1989, 18 GF-LW, de 28-6-19, pp. 5-33, p. 19. Cf. FANN, K., 1971, p. 3. Cf. BLACK, M., 1971, p. 1. Cf. STROLL, A., 1994, p. 69. Cf. AMMERELLER, E. In: AMMERELLER e FISCHER, 2004, p. 97. Em relação à difícil tarefa de acompanhar as liçôes de Wittgenstein, Norman Malcolm confessara: "Decidi empenhar-me a fundo e, ao longo do ano, fiz um grande esforço para acompanhar o seu pensamento durante aqueles encontros, um esforço que me deixava, ao fim de duas horas, intelectualmente exausto. Cf. MALCOLM, 1958, p. 27. 
Uma das principais fontes de nossa falta de compreensão é que não dominamos uma visão clara do uso de nossas palavras. - Falta à nossa gramática uma disposição clara. Uma apresentação perspícua transmite a compreensão, que consiste em 'ver conexóes'. Daí a importância de achar e de inventar casos intermediários.

O conceito de uma apresentaçáo perspícua é de fundamental importância para nós. Ele designa a nossa forma de exposição, a forma como olhamos para as coisas (Esta é uma 'visão de mundo'?) (TS 227b, p. $88=\mathrm{PU}$, $\$ 122)^{18}$.

Embora, na passagem supracitada, o próprio Wittgenstein afirme ser o método de "fundamental importância" e que ele "designa a forma" pela qual expóe seu pensamento, isso divide opiniôes e é atualmente matéria de grande polêmica entre os seus intérpretes.

De um lado, temos um entendimento negativo sobre a importância do "novo método". Nesse grupo se insere Saul Kripke, que considera o modo de Wittgenstein escrever como uma falha estrutural, como uma incompetência do autor ou "falta de habilidade" para escrever convencionalmente, devido à sua permanente contradição não resolvida entre náo querer apresentar teses em Filosofia e, ao mesmo tempo, apresentar teses céticas (KRIPKE, 1982) ${ }^{19}$ De maneira semelhante, Stephen Hilmy interpreta o "novo método" de Wittgenstein como uma "lacuna pessoal", "uma idiossincrasia estilística" advinda de uma insatisfação meramente psicológica, uma constante sempre presente nos seus escritos ${ }^{20}$.

De outro lado, há um grupo de acordo quanto à "importância fundamental” do método para o pensamento posterior de Wittgenstein. Entre

\footnotetext{
${ }^{18}$ Original: "Es ist eine Hauptquelle unseres Unverständnisses, daß wir den Gebrauch unserer Wörter nicht übersehen. - Unserer Grammatik fehlt es an Übersichtlichkeit. - Die übersichtliche Darstellung vermittelt das Verständnis, welches eben darin besteht, daß wir die 'Zusammenhänge sehen'. Daher die Wichtigkeit des Findens und des Erfindens von Zwischengliedern. Der Begriff der übersichtlichen Darstellung ist für uns von grundlegender Bedeutung. Er bezeichnet unsere Darstellungsform, die Art, wie wir die Dinge sehen. (Ist dies eine 'Weltanschauung'?)"

19 Por não nos ocupar, neste trabalho, com a interpretação de Kripke sobre Wittgenstein e com a discussão de Wittgenstein ser ou não ser cético, reportamos o leitor interessado para os seguintes trabalhos, os quais tratam diretamente do tema: SMITH, 2002; KARCZMARCZYK, 2012, 2013; SIQUEIRA (2009) e GILMORE (1999).

${ }^{20}$ Hilmy ressalta a insatisfaçáo de Wittgenstein como um dado psicológico e não metodológico: o fato de a primeira parte das Investigaçóes Filosóficas ter sido escrita como um álbum não significa mais do que uma idiossincrasia estilística completamente irrelevante para o método filosófico (HILMY, 1987, p. 15-25).
} 
eles, encontra-se Anthony Kenny. Este afirma que "o método tem o mérito de receber lugar central no pensamento tardio de Wittgenstein" (KENNY, 1984 , p. 42-3) ${ }^{21}$. Na esteira de Kenny, Gordon Baker e Peter Hacker, os quais talvez sejam os maiores defensores da posição de que o método é de suma importância para se entender Wittgenstein, enfatizam que, "embora o conceito de übersichtlich Darstellung de Wittgenstein em si não seja claro, ele é obviamente importante" (BAKER, 2004, p. 22), "um fio condutor do pensamento posterior de Wittgenstein" (BAKER, 1991, p. 7-8; BAKER, 2004, p. 22).

Há, ainda, outros autores que escreveram obras ou parte delas dedicadas a defender a importância do método filosófico de Wittgenstein, entre os quais citamos David Stern (20011), Avrum Stroll (1994), Nicolay Milkov (2012), Erich Ammereller e Eugen Fischer (2004), Arley Moreno (2009), Mauro Engelmann (2013), Richard Gilmore (1999) e Gilberto Souza (2017).

$\mathrm{Na}$ introdução de sua obra dedicada ao método de Wittgenstein, nas Philosophische Untersuchungen, Fischer e Ammereller (2004, p. ix.) assinalam:

A abordagem filosófica posterior de Wittgenstein é pouco convencional. As observaçóes que afirmam a sua concepção dos problemas filosóficos e do método pertencem às seções mais marcantes das Investigaçōes Filosóficas: mesmo uma leitura superficial de suas observaçóes sobre a natureza da filosofia é suficiente para fazer o leitor perceber que os pensamentos de Wittgenstein sobre esta matéria estão notavelmente em desacordo com as concepçóes tradicionais do que é a filosofia. Curiosamente o suficiente, estas observaçôes, apesar de serem as mais negligenciadas, como vários estudiosos têm enfatizado, destacam os aspectos mais revolucionários do seu trabalho posterior e claramente constitui a chave para a adequada compreensão. ${ }^{22}$.

O nosso pensamento se dirige, de forma geral, em concordância com a segunda linha de interpretação, ou seja, concebendo que o novo método é

\footnotetext{
${ }^{21}$ Concordam, também, com essa posição: HACKER (1990, p. 488-491 e 531-545); BAKER (1991, p. 39); BAKER (2004, p. 22 e 26) e KENNY (2006, p. XII).

${ }^{22}$ Original: "Wittgenstein's later philosophical approach is rather unconventional. The remarks that state his conception of philosophical problems and method belong to the most striking sections of the Philosophical Investigations: even a cursory reading of his remarks on the nature of philosophy suffices to make the reader realize that Wittgenstein's thoughts on this matter are strikingly at odds with traditional conceptions of what philosophy is about. Remarkably enough, these remarks also belong to the most neglected - and this even though, as various scholars have emphasized, they highlight the most revolutionary aspects of his later work and clearly hold the key to its proper understanding."
} 
indispensável para a compreensão das observações filosóficas que Wittgenstein empreendeu a partir de sua volta a Cambridge.

Wittgenstein jamais descreveu explicitamente em que consiste o seu "novo método". Expôs apenas indicações quanto à sua natureza. Assim, entre as suas inúmeras indicaçôes, podemos mencionar algumas que julgamos estar entre as mais importantes para a presente reflexão:

a) Wittgenstein dedica uma grande parte dos seus trabalhos a rejeitar o ideal de método científico presente na Filosofia. Para isso, ele tenta expor, em suas observaçóes, as marcas do "espírito" do autor, o qual procura distanciar-se das obras dos cientistas e filósofos científicos, bem como enfatiza a diferença entre Filosofia e Ciência.

b) Distante do estilo do TLP, nas PU, presenciam-se os interlocutores, as frases curtas e espontâneas próximas à oralidade, abundantes interrogaçôes, inúmeras objeções aos juízos que o senso comum, habitualmente, toma como evidentes e convidam ao diálogo e à discussão.

c) Wittgenstein notou que, para se alcançar a clareza, em suas investigaçóes filosóficas, havia a necessidade de filosofar de alguma outra maneira que não fosse mediante a asserção de doutrinas. Assim, em suas observaçóes, não há teses que afirmam que as coisas devem ou não ser, como uma condição de possibilidade do nosso pensamento ou raciocínio (TS 227b, p. $89=\mathrm{PU}, \mathbb{S}$ $128)^{23}$.

d) A concepção de Filosofia, para Wittgenstein, não é a de uma ciência da natureza, ou de uma teoria, mas uma atividade cujo fim é o esclarecimento lógico dos pensamentos anteriormente turvos e indistintos, por causa das confusôes das quais ela (a Filosofia) está repleta. (TS 204, p. 16r = TLP $4.122)^{24}$.

e) A investigação filosófica, segundo Wittgenstein, seria apenas a descrição dos usos dos conceitos. Nesse sentido, o método (ou métodos) de esclarecimento é descritivo. Os usos de expressóes problemáticas são descritos no seu contexto

${ }^{23}$ Original: "Wollte man Thesen in der Philosophie aufstellen, es könnte nie über sie zur Diskussion kommen, weil Alle mit ihnen einverstanden wären."

${ }^{24}$ Original: "[...] Das Bestehen solcher internen Eigenschaften und Relationen kann aber nicht durch Sätze behauptet werden, sondern es zeigt sich in den Sätzen, welche jene Sachverhalte darstellen und von jenen Gegenständen handeln.[...]". Ver também: TS 204, p. 15r = TLP 4.112; TS 204, p. 15r = TLP 4.111; TS 204, p. 9r = TLP 3.324; TS 227b, p. 84 = PU, \$109; TS 227b, p. $89=$ PU, \$\$126-7. 
elaborado e nos jogos de linguagem aos quais são incorporados (TS 227b, p. $84=$ PU $₫ 109)^{25}$.

f) Wittgenstein não se propóe explicar a natureza dos fenômenos, mas altera as perguntas que parecem assemelhar-se a um problema, apresentando um conjunto de casos similares um ao lado do outro, a fim de eliminar a perplexidade.

g) Wittgenstein revela o novo método como um "lugar de apoio" (a real resting place) para realizar e/ou "resolver um propósito" (something settled). Em outras palavras, o método seria o ponto de apoio para a realização do propósito, a saber: permitir variar um ponto de vista apresentado inicialmente como expressáo definitiva e absoluta de uma verdade (RHEES, 1981, p. 125-126) ${ }^{26}$.

h) Não há nada de hipotético nas observações filosóficas de Wittgenstein que possa tornar necessária a confirmação empírica, ou a desconfirmação, ou que possa ser mais ou menos provável. A investigação é totalmente a priori e assim também são as observaçôes gramaticais arranjadas para resolver os problemas filosóficos (TS 227b, p. $84=$ PU, $\$ 109)^{27}$.

i) Uma tarefa importante reservada ao filosofar consiste na dissolução dos problemas filosóficos. Isso significa que não se procura responder de forma positiva a uma questão; pelo contrário, por meio de uma análise minuciosa, anula-se a pergunta e o problema se desfaz na anulação. Sobre isso, observa o filósofo: "Os problemas são dissolvidos no sentido próprio [do termo] - como um torrão de açúcar na água.” (TS 213, p. 421 = BT, $\$ 89$, p. 310 28.

${ }_{25}$ Original: "[...] Und wir dürfen keinerlei Theorie aufstellen. Es darf nichts Hypothetisches in unsem Betrachtungen sein. Alle Erklärung muß fort, und nur Beschreibung an ihre Stelle treten. Und diese Beschreibung empfängt ihr Licht, d.i. ihren Zweck, von den philosophischen Problemen. Diese sind freilich keine empirischen, sondern sie werden durch eine Einsicht in das Arbeiten unsererSprache gelöst, und zwar so, daß dieses erkannt wird: entgegen einem Trieb, es mißzuverstehen. Diese Probleme werden gelöst, nicht durch Beibringen neuer Erfahrung, sondern durch Zusammenstellung deslängst Bekannten [...]."

${ }^{26}$ Original: "Yet, I have reached a real resting place. I know that my method is right. My father was a business man, and I am a business man: I want my philosophy to be business-like, to get something done, to get something settled."

27 Original: "[...] Und wir dürfen keinerlei Theorie aufstellen. Es darf nichts Hypothetisches in unsem Betrachtungen sein. Alle Erklärung muß fort, und nur Beschreibung an ihre Stelle treten. Und dieseBeschreibung empfängt ihr Licht, d.i. ihren Zweck, von denphilosophischen Problemen. Diese sind freilich keine empirischen, sondern sie werden durch eine Einsicht in das Arbeiten unsererSprache gelöst, und zwar so, daß dieses erkannt wird: entgegen einem Trieb, es mißzuverstehen. Diese Probleme werden gelöst, nicht durch Beibringen neuer Erfahrung, sondern durch Zusammenstellung deslängst Bekannten [...]."

${ }^{28}$ Original: "Wie ich Philosophie betreibe, ist es ihre ganze Aufgabe, den Ausdruck so zu gestalten, daß gewisse Beunruhigungen //Probleme // verschwinden. (Hertz.) Wenn ich Recht habe, so müßen sich philosophische Probleme wirklich restlos lösen laßen, im Gegensatz zu allen andern. Wenn ich sage: Hier 
j) Os movimentos revistos do pensamento podem ser interpretados como variaçóes de uma e mesma ideia: um movimento que ora procura aproximação, tentando focar os pormenores que escapam a olho nu, e um movimento que ora procura o afastamento, tentando obter uma visão do todo. Era como se Wittgenstein pudesse ver e pensar as questóes sobre as quais ele obsessivamente se debatia, sob perspectivas e abordagens diferentes, e pudesse, a partir de diversas tentativas de esclarecê-las, escapar à hipnose da maneira habitual de apresentar, aproximar-se do centro da questáo e compreender melhor o papel, as conexóes e os limites dos conceitos reais. Para isso, frisava: "Estou a filosofar agora como uma velha que está sempre a perder qualquer coisa e a procurá-la: ora os óculos, ora as chaves" (MS 176, p. 54v-55r = ÜG, $\$ 532) .{ }^{29}$

k) Enquanto, no TLP, a noção de linguagem é analisada de forma isolada e desvinculada das circunstâncias concretas da vida, as obras tardias de Wittgenstein se referem à importância dos contextos nos quais os signos linguísticos são inseridos, pois o que uma pessoa expressa não depende simplesmente do que ela diz, mas das circunstâncias que mostram qual jogo de linguagem está sendo jogado: "Como as palavras são entendidas não é dito apenas por elas" (MS 116, p. $341=\mathrm{Z}, \$ 144)^{30}$. Assim, as palavras adquirem sentido somente no contexto de uma proposição, uma proposição adquire sentido somente em um "contexto" de uso no jogo de linguagem e um "jogo de linguagem" tem sentido apenas no contexto de uma "forma de vida".

l) Segundo Wittgenstein, a atividade filosófica tem função terapêutica e visa substituir as formas ideais de expressão por formas da linguagem ordinária, a auxiliar alguém a libertar-se do fascínio e incômodo de certas expressóes, assim como a enunciar usos habituais e inventar novos usos. Nesse sentido, as palavras deveriam ser reconduzidas do seu sentido metafísico ao sentido trivial e familiar que os falantes lhes atribuem, no dia a dia (TS 227b, p. $86-87=$ PU, $\$ 116)^{31}$.

sind wir an der Grenze der Sprache, so scheint //klingt // das immer, als wäre hier eine Resignation nötig, während im Gegenteil volle Befriedigung eintritt, da keine Frage übrig bleibt. Die Probleme werden im eigentlichen Sinne aufgelöst - wie ein Stück Zucker im Wasser. 'Ver também: TS 213, p. $411=$ BT, \$88, p. 304; TS 213, p. 414-415 = BT, \$89, 306; TS 227b, p. 87 = PU, \$118.

${ }^{29}$ Original: "Ich philosophiere jetzt, wie eine alte Frau, die fortwährend etwas verlegt \& es wieder suchen muß; einmal die Brille, einmal den Schlüsselbund."

${ }^{30}$ Original: "Wie ein Wort verstanden wird, das sagen Worte allein nich." Ver também: TS 204, p. 8r = TLP, 3.3; TS 227b, p. 37-38 = PU, $\$ 43$ e TS 227b, p. 232-233 = PU, $\$ 412$.

${ }^{31}$ Original: "Wir führen die Wörter von ihrer metaphysischen, wieder auf ihre alltägliche Verwendung zurück." 
Por conseguinte, como não há definições e poucas menções diretas a respeito do "novo método", nos escritos filosóficos de Wittgenstein (embora haja inúmeras declaraçôes pessoais que não citamos), colhemos algumas observações que nos permitem formar uma concepção razoavelmente clara da natureza e objetivo do "novo método".

Assim, a crítica filosófica que Wittgenstein empreende em relação à psicologia e à matemática, trabalho concentrado desde sua volta a Cambridge (1929) até sua morte (1951), se configura como uma prática ou aplicação do "novo método" filosófico, anunciado em 1929, aos conceitos psicológicos. Nesse sentido, podemos passar à exposição do tema da Filosofia da Psicologia, para compreender a perspectiva crítica de Wittgenstein pela qual emergem e se relacionam os aspectos mencionados do "novo método".

\section{A Filosofia da PSICOLOGIA COMO UMA CRÍtICA À CIÊNCIA PSICOLÓGICA}

Com relação ao escopo da Filosofia da Psicologia, nos escritos de Wittgenstein, a despeito de não se poder traçar um limite claro e definitivo neles, por várias razões, mas principalmente por encontrar conceitos e reflexóes referentes ao tema dispersos em vários outros escritos, desde a preparação do TLP até Über Gewißheit (ÜG), uma questão que Joachim Schulte levanta pode ser problematizada: a Filosofia da Psicologia de Wittgenstein é um trabalho à parte e autônomo ou é parte de um projeto maior, subordinada aos interesses mais gerais da sua Filosofia (SCHULTE, 1995, p. 1) ${ }^{32}$ ? Por um lado, especialistas com a autoridade de G. H. Von Wright e do próprio Schulte, entre outros, consideram que as observaçôes do último Wittgenstein sobre Filosofia da Psicologia representam realmente algo novo, uma reconfiguração de temas e conceitos (MARQUES, 2007, p. 8-9). Por outro lado, Budd e Hacker entendem que esse tema específico é derivado e subordinado à sua concepção mais geral de Filosofia ${ }^{33}$. Essa problematização pode ser reduzida, senão eliminada, quando fizermos uma leitura das novas observaçóes do próprio Wittgenstein como uma retomada que se insere em um novo contexto, mas cujo pano de fundo indispensável é o TLP.

No caso particular da Filosofia da Psicologia, apenas recentemente começaram a aparecer alguns trabalhos dedicados a explorar o alcance das

\footnotetext{
${ }^{32}$ Original: "Do the typescript and manuscripts on the philosophy of psychology whinch Wittgenstein wrote in the years 1946 to 1949 constitute a philosophical work or, perhaps, a series of philosophical works? Or do these typescripts and manuscripts form different versions of one major work?"

${ }^{33}$ Cf. BUDD (1993, xi) e HACKER (2010, p. 286).
} 
consideraçôes inovadoras de Wittgenstein com relação ao sujeito psicológico que se estendem para além dos estreitos limites do cartesianismo, do behaviorismo, da psicanálise e dos pretensiosos fundamentos de uma psicologia que se quer científica.

A Filosofia da Psicologia concebida por Wittgenstein de forma sistemática, embora tenha origem em meados de 1940, tornou-se conhecida muito tardiamente. Por volta de 1980, as observaçóes do autor feitas como anotaçôes são publicadas, resultando em Bemerkungen über die Philosophie der Psychologie (BPP). Pouco mais tarde, em 1982, surge o primeiro volume de Letzte Schriften zur Philosophie der Psychologie (LSPP) e, nos anos seguintes, segue-se o segundo volume. Antes disso, porém, parte desses manuscritos foi alvo dos editores e publicado sob o já mencionado título Über Gewißheit ( $\ddot{U} G$ ), em 1969.

Sabe-se agora que tanto BPP quanto LSPP estâo diretamente ligados à $\mathrm{PU}$, obra referencial da fase final do pensamento de Wittgenstein, já que grande parte dela foi elaborada no tempo em que o filósofo dava aulas sobre temas da Psicologia. Além disso, sabe-se também que os escritos que constituem ÜG pertencem aos manuscritos dedicados à Filosofia da Psicologia de Wittgenstein e que, nesses textos, o autor faz inovaçóes profundas quanto ao tratamento dos termos psicológicos, oferecendo, assim, material para a renovação do estatuto teórico da Psicologia e de suas pretensôes científicas, bem como para a delimitação da Filosofia e do seu método.

A ciência psicológica se desenvolveu, principalmente, no fim do século XIX e início do século XX, como uma ciência fundamentada em investigações empíricas, realizadas por meio de metodologias experimentais e matemático-estatísticas sobre o comportamento. Segundo essas metodologias, a experiência ou a vivência subjetiva teria caráter secundário, em favor de uma fundamentação do comportamento, a partir de um observador externo.

Contudo, a Filosofia da Psicologia de Wittgenstein não se insere nessa perspectiva experimental, porque o que interessa a ele, em sua investigação, são os fundamentos ou princípios que constituem a análise e o uso dos conceitos psicológicos.

Para a matemática é possível uma investigação muito análoga à nossa investigação da psicologia. Ela é tão pouco uma investigação matemática quanto a outra é uma investigação psicológica. Nela não se calcula, p. 
ex. não é logicista. Poderia merecer o nome de uma investigação dos "fundamentos da matemática" (MS 138, 12a = LSPP I, \$792) 34 .

A abordagem desenvolvida por Wittgenstein não se concentra em uma explicação causal, mas sim em uma descrição das exteriorizaçôes dos conceitos psicológicos proferidas na linguagem. Nessa perspectiva, a psicologia não deveria tratar o âmbito do psíquico da mesma forma como a física trata de seus objetos:

Um paralelo enganador: a psicologia trata dos processos na esfera da psicologia como a física trata dos processos da esfera do físico. Ver, ouvir, pensar, sentir, querer não são no mesmo sentido objetos da psicologia como o movimento dos corpos e os fenômenos elétricos, etc. são objetos da física. E isso se vê no fato de o físico ver, ouvir, refletir sobre esses fenômenos e informar-nos acerca deles, enquanto que o psicólogo observa as exteriorizações (o comportamento) do sujeito (TS 227 b, p. $283=\mathrm{PU}, \$ 571)^{35}$.

$\mathrm{O}$ que Wittgenstein quer enfatizar, na investigação dos conceitos psicológicos, não deve ser fundamentado na análise de um fenômeno físico, ou seja, não se trata de uma pesquisa científica ${ }^{36}$. Para ele, os fenômenos

${ }^{34}$ Original: "Es ist für die Mathematik eine Untersuchung möglich ganz analog der philosophischen Untersuchung der Psychologie. Sie ist ebensowenig eine mathematische, wie die andre eine psychologische. In ihr wird nicht gerechnet, sie ist also z.B. nicht Logistik. Sie könnte den Namen einer Untersuchung der 'Grundlagen der Mathematik' verdienen."

${ }^{35}$ Original: "Irreführende Parallele: Psychologie handelt von den Vorgängen in der psychischen Sphäre, wie Physik in der physischen.Sehen, Hören, Denken, Fühlen, Wollen, sind nicht im gleichen die Gegenstände der Psychologie, wie die Bewegungen der Körper, die elektrischen Erscheinungen, etc., Gegenstände der Physik. Das siehst du daraus, daß der Physiker diese Erscheinungen sieht, hört, über sie nachdenkt, sie uns mitteilt, und der Psychologe die Äußerungen (das Benehmen) des Subjekts beobachtet."

${ }^{36}$ Embora Wittgenstein conhecesse a ciência do seu tempo, inclusive a Psicologia, sua preocupação fundamental não era desenvolver a Psicologia como ciência. Quanto à ciência, é possível constatar, no TLP, mençōes a algumas obras científicas, como The Principles of Mechanics de Heinrich Hertz, Philosophiae Naturalis Principia Mathematica, de Isaac Newton, e The Origin of Species, de Charles Darwin, bem como, nas PU, as obras The Principles of Psychology, de William James, Gestalt Psychology, de Wolfgang Köhler, e The Chemical History of a Candle, de Michael Faraday. Quanto à Psicologia, ele não pretendia desenvolver uma pesquisa científica que pudesse promover um saber empírico; queria apresentar uma consideraçáo conceitual dos termos e afirmaçóes utilizados pela Psicologia, por meio dos procedimentos de enunciação, invenção, comparaçáo e diferenciação dos múltiplos jogos de linguagem, do diagnóstico das confusōes conceituais, da realização de uma reflexão filosófica 
psicológicos, por serem vivências na primeira pessoa (vivências próprias e exclusivas do sujeito $)^{37}$, não podem ser reduzidos a uma explicação fisiológica: "O conceito psicológico paira intocado por cima da explicação fisiológica. E a natureza do nosso problema torna-se por isso mais clara" (MS 138, p. 10a $=$ LSPP I, \$777) ${ }^{38}$. Dessa maneira, os escritos sobre a Filosofia da Psicologia propostos por Wittgenstein teriam como fim a obtenção de uma apresentação perspicua dos conceitos psicológicos expressos na linguagem.

O conceito de apresentação perspicua (übersichtlich Darstellung) diz respeito ao nosso modo de apresentar [Darstellungsform] as coisas, ao modo como as coisas aparecem e, concomitantemente, ao modo como podemos fazer conexôes e relaçóes intermediárias entre os conceitos ${ }^{39}$. Assim, esse conceito mantém, nos escritos de Wittgenstein, relação com o tema da Psicologia, da cultura e das cores, conforme afirma Hebeche (HEBECHE, 2002, p. 59-70), mas também com outros temas, como a matemática, a linguagem, a lógica e a ética. E o propósito de Wittgenstein, com a realização de uma apresentação perspícua dos conceitos psicológicos, seria dissolver problemas metafísicos que estariam há tempos na Psicologia, porém, que, no fundo, nada mais seriam que problemas conceituais, isto é, confusôes linguísticas, e libertar os filósofos da completa escuridão e da quase irresistível tentação do método da ciência:

Os filósofos têm constantemente diante de seus olhos o método da ciência e são irresistivelmente tentados a colocar e a responder a questôes do mesmo modo que a ciência faz. Essa tendência é a verdadeira fonte da metafísica, e leva o filósofo à mais completa escuridáo (TS 309, p. 28 = BB, p. 18) (0. $^{40}$

terapêutica de esclarecimento conceitual e da definição do âmbito concreto de uso das investigaçôes psicológicas (MARQUES, 2007, p. 25; BUUD, 1993). Quanto a essa definição precisa dos distintos campos investigativos, Wittgenstein, segundo Pareja, distingue as tarefas da Filosofia e da Psicologia: enquanto o psicólogo se ocupa com a observação dos fenômenos que se desenvolve no âmbito empírico, o filósofo fixa sua atenção na análise conceitual (GIL DE PAREJA, 1992, p. 346).

${ }^{37}$ A relação entre fenômenos psicológicos e vivência, na primeira pessoa, concerne à particularidade pertencente ao âmbito dos conceitos mentais no que se refere a um suposto "acesso exclusivo" ao fenômeno mental, ou seja, apenas o indivíduo que possui um fenômeno mental (crença, intenção etc.) pode acessá-lo, enquanto terceiros possuiriam apenas um acesso indireto.

${ }^{38}$ Original: "Der psychologische Begriff schwebt über der physiologischen Erklärung unberührt. Und die Natur unsres Problems wird dadurch klarer."

39 Já mencionamos anteriormente, na nota 15 acima, o problema inerente à tradução do termo, bem como a nossa versão de preferência.

${ }^{40}$ Original: "Philosophers constantly see the method of science before their eyes, and are irresistibly tempted to ask and answer questions in the way science does. This tendency is the real source of metaphysics, and leads the philosopher into complete darkness." 
Esse procedimento metodológico que Wittgenstein aplica, na Filosofia da Psicologia, segue o proposto já nos escritos a partir do ano de 1929, qual seja, de ser uma investigação puramente descritiva que não pretende levantar hipóteses ou construir teorias explicativas de caráter sistemático, hermético e conclusivo. A esse respeito, o filósofo adverte:

Era certo dizer que nossas considerações não deviam ser considerações científicas. A experiência "de que isto ou aquilo possa ser pensado contra nosso preconceito" - o que quer que isso signifique - não podia nos interessar. (A concepçáo pneumática do pensamento.) E não devemos construir nenhuma espécie de teoria. Não deve haver nada de hipotético nas nossas considerações. Toda explicação deve desaparecer e ser substituída apenas por descriçāo. E esta descrição recebe sua luz, isto é, sua finalidade, dos problemas filosóficos. Estes problemas não são empíricos, mas são resolvidos por meio de um exame do funcionamento de nossa linguagem, de tal modo que este seja reconhecido: contra o impulso de mal compreendê-lo. Os problemas são resolvidos não pelo acúmulo de nova experiência, mas pela combinação do que é já há muito tempo conhecido. A filosofia é uma luta contra o enfeitiçamento do nosso entendimento pelos meios da nossa linguagem (TS 227b, p. $84=\mathrm{PU} \$ 109)^{41}$.

É possível perceber, nessa passagem, que a rejeição de Wittgenstein em construir uma teoria filosófica mantém vínculo com uma particular concepção a propósito daquilo que o próprio filósofo toma como "investigaçáo filosófica" (TS 229, p. 255 = BPP I, $\$ 949)^{42}$. Para ele, a investigação filosófica, inclusive a investigação sobre conceitos psicológicos, seria de ordem conceitual e nada mais que a descrição dos usos dos conceitos e, no caso da Psicologia, dos conceitos psicológicos.

${ }^{41}$ Original: "Richtig war, daß unsere Betrachtungen nicht wissenschaftliche Betrachtungen sein durften. Die Erfahrung, 'daß sich das oder das denken lasse, entgegen unserm Vorurteil' - was immer das heißen mag - konnte uns nicht interessieren. (Die pneumatische Auffassung des Denkens.) Und wir dürfen keinerlei Theorie aufstellen. Es darf nichts Hypothetisches in unsern Betrachtungen sein. Alle E $r k l$ ä $r u n g$ mußfort, und nur Beschreibung an ihre Stelle treten. Und diese Beschreibung empfängt ihr Licht, d.i. ihren Zweck, von den philosophischen Problemen. Diese sind freilich keine empirischen, sondern sie werden durch eine Einsicht in das Arbeiten unserer Sprache gelöst, und zwar so, daß dieses erkannt wird: entgegen einem Trieb, es mißzuverstehen. Die Probleme werden gelöst, nicht durch Beibringen neuer Erfahrung, sondern durch Zusammenstellung des längst Bekannten. Die Philosophie ist ein Kampf gegen die Verhexung unsres Verstandes durch die Mittel unserer Sprache."

${ }^{42}$ Original: "Philosophische Untersuchungen: begriffliche Untersuchungen. Das Wesentliche der Metaphysik: daßihr der Unterschied zwischen sachlichen und begrifflichen Untersuchungen nicht klar ist. Die metaphysische Frage immer dem Anscheine nach eine sachliche, obschon das Problem ein Begriffliches ist." 
Nossa consideração é, por isso, gramatical. E essa consideração traz luz para o nosso problema, afastando os mal-entendidos. Mal-entendidos que concernem ao uso das palavras; provocados, entre outras coisas, por certas analogias entre as formas de expressão em diferentes domínios da nossa linguagem. Muitos deles são afastados ao se substituir uma forma de expressão por outra; isto se pode chamar de "análise" de nossas formas de expressáo, pois esse processo se assemelha, muitas vezes, a uma decomposição (TS 227b, p. $76=\mathrm{PU}, \$ 90)^{43}$.

Para Wittgenstein, tanto a Psicologia quanto a Matemática da sua época estariam envolvidas em uma confusão gramatical que impediria a compreensão correta dos conceitos usados por ambas as ciências, visto que, na Psicologia, existem métodos experimentais, enquanto, na Matemática, existem métodos demonstrativos - e, em ambas, existe confusão conceitual. Por essa razão é que, em suas observaçóes, ele faz um paralelo entre uma e outra, com o objetivo de realizar uma investigação de caráter conceitual, dado que o método da Psicologia pressupóe o uso dos conceitos na linguagem que não são alcançados pelo método experimental, porque, segundo Wittgenstein, confusão conceitual e método experimental passam um pelo outro, de forma desaprumada: "A existência do método experimental nos faz crer que teríamos os meios para nos livrarmos dos problemas que nos inquietam; embora problema e método passem um pelo outro desaprumados" (MS 144, p. 44r = PU, II, XIV) ${ }^{44}$.

De uma perspectiva wittgensteiniana, pode-se dizer que não é possível nos livrarmos dos "problemas que nos inquietam" na Filosofia e na Psicologia, utilizando o "método experimental", pois este não resolve questóes de caráter conceitual. E, para resolvermos tais questóes e ficarmos em paz com elas, Wittgenstein sugere treinarmos para alcançar uma perspicuidade em nossa visão e apresentação dos usos conceituais, que se dá somente mediante a aplicação no "novo método".

\footnotetext{
${ }^{43}$ Original: "Unsere Betrachtung ist daher eine grammatische. Und diese Betrachtung bringt Licht in unser Problem, indem sie Mißverständnisse wegräumt. Mißverständnisse, die den Gebrauch von Worten betreffen hervorgerufen unter anderem durch gewisse Analogien, zwischen den Ausdrucksformen in verschiedenen Gebieten unserer Sprache. - Manche von ihnen lassen sich beseitigen, in dem man eine Ausdrucksform durch eine andere ersetzt; dies kann man ein 'Analysieren' unsrer Ausdrucksformen nennen, denn der Vorgang hat eine Ähnlichkeit mit einem Zerlegen."

${ }_{44}$ Original: "Das Bestehen der experimentellen Methode läßt uns glauben, wir hätten das Mittel, die Probleme, die uns beunruhigen, los zu werden; obgleich wenn auch Problem \& Methode windschief an einander vorbei laufen."
} 


\section{CONSIDERAÇóEs FINAIS}

Os compromissos filosóficos de Wittgenstein, a partir de 1929, incluíram as retomadas das suas convicções filosóficas do início de sua carreira profissional, isto é, das concepçôes tractarianas de "método correto da Filosofia" e de "Filosofia da Psicologia". Esses pressupostos irrefletidos se tornaram alvos favoritos das novas análises, após 1929, em várias direções e sob múltiplas perspectivas, dada a exigência da natureza da nova investigação em curso.

As exploraçôes em torno do ainda informe "novo método" filosófico se deram, a princípio, por meio de declaraçóes pouco explícitas e de observaçôes enigmáticas, tendo ganhado corpo com traços distintivos, sempre em contraste com o método científico. As exploraçóes acerca da "Filosofia da Psicologia" mostraram-se frutíferas, ao longo do tempo, e de grande valor para o pensamento contemporâneo, tanto em termos de "método" para a filosofia quanto à natureza e status da própria Psicologia.

Os aspectos principais do "novo método" filosófico de Wittgenstein, como procuramos expor neste texto, são praticamente negligenciados pela maioria dos comentadores do filósofo e pelos investigadores e acadêmicos de nosso tempo. Contra isso, vale ressaltar quatro de nossas observaçóes, feitas acima: a abordagem sobre o "novo método" filosófico de Wittgenstein é pouco convencional quanto ao modo de escrita, é negligenciada (na prática) pela maioria dos comentadores do autor, é revolucionária em comparação com a tradição filosófica e constitui a "chave" "indispensável" para a adequada compreensão das observações filosóficas de Wittgenstein.

Tudo isso significa que a Filosofia da Psicologia é uma prática ou uma aplicação do "novo método" filosófico que Wittgenstein empreendeu, após a publicação do TLP (1929) até sua morte, em 1951. Trata-se de uma relação prática e necessária entre ambos os temas: "novo método" e "Filosofia da Psicologia”. Ou seja, só é possível compreender adequadamente as observaçóes sobre a Filosofia da Psicologia, nos escritos tardios de Wittgenstein, pelo filtro do "novo método" e só é possível compreender a natureza e características do "novo método", vendo-o aplicado nas mencionadas observaçôes filosóficas. Por fim, podemos concluir que as observaçóes de Wittgenstein sobre a Filosofia da Psicologia constituem uma prática ou aplicação do "novo método" e, em vários aspectos, estão necessariamente relacionadas. 
SOUZA, G. F. The philosophy of psychology and the philosophical "new method" in Wittgenstein's late writings: a practical and necessary relation. Trans/form/ação, Marília, v. 43, p. 145-166, 2020. Edição Especial.

\begin{abstract}
The main purpose of this article is to present the themes of the philosophical "new method" and the "philosophy of psychology" in Ludwig Wittgenstein's late writings as practically and necessarily related. For the proposed, our expository strategy follows the following order: we analyzed the relatively unreasonable philosophical presuppositions that determine the young Ludwig's view of the "correct method of philosophy" and of "philosophy of psychology"; we interpreted the philosophical turn of 1929 as committed to presenting the still-informed face of the "new method" and to critically revisiting the TLP targets under this new methodological perspective; and we considered Wittgenstein's philosophy of psychology inserted in a different perspective from the perspective of the psychological science of the late nineteenth and early twentieth century based on empirical investigations. These observations are properly a practice of the "new method" of perspicuous presentation and they are characterized as a key and necessary aspect, a filter, for the understanding of the philosopher's observations about psychology, and his goal in dissolving the metaphysical problems present there.
\end{abstract}

Keywords: Philosophy. Wittgenstein. Philosophy of Psychology. Method.

\title{
LISTA DE ABREVIATURAS 45
}

MS/TS Wittgenstein's Nachlass: The Bergen Electronic Edition.

TLP Tractatus Logico-Philosophicus.

LWL Wittgenstein's lectures, Cambridge, 1930-1932.

MWL Wittgenstein's Lectures in 1930-33.

BB The Blue (BB) und Brown Books (BrB).

BT The Big Typescript.

$\mathbf{Z}$ Zettel.

PB Philosophical Remarks/Philosophische Bemerkungen.

BGM Bemerkungen über die Grundlagen der Mathematik.

PU Philosophische Untersuchungen/Philosophical Investigations.

\footnotetext{
${ }^{45}$ As citaçôes das obras de Wittgenstein, ao longo deste artigo, foram referenciadas pelas siglas acompanhadas do número da página ou parágrafo referente. E as referências aos Manuscritos (MS) e Datiloscritos (TS) citados são do Nachlass (WN), conforme abreviatura apresentada.
} 
BPP I Remarks on the Philosophy of Psychology/Bemerkungen über die Philosophie der Psychologie. Vol. 1 .

BPP II Remarks on the Philosophy of Psychology/Bemerkungen über die Philosophie der Psychologie. Vol. 2.

LSPP I Last Writings on the Philosophy of Psychology/Letzte Schriften über die Philosophie der Psychologie. Vol. 1.

LSPP II Last Writings on the Philosophy of Psychology/Letzte Schriften über die Philosophie der Psychologie. Vol. 2.

ÜG Über Gewißheit/On Certainty.

\section{REFERÊNCIAS}

AMMERELLER, E. Puzzles about rules following - PI 185-242, p. 127-146. In: E. Ammereller, E. Fischer. (Eds.). Wittgenstein at Work: Method in the Philosophical Investigations. London: Routledge, 2004.

AMMERELLER, E., FISCHER, E. (Eds.). Wittgenstein at Work: Method in the Philosophical Investigations. London: Routledge, 2004.

ARRINGTON, R., GLOCK, H-J. (Eds.). Wittgenstein's Philosophical Investigations: text and context. London: Routledge, 1991.

BAKER, G. Philosophical Investigations section 122: Neglected Aspects,1991. In: R. Arrington, H-J, Glock (Eds.). Wittgenstein's Philosophical Investigations: text and context. London: Routledge, 1991.

BAKER, G. Wittgenstein's Method. Neglected Aspects. London: Blackwell Publishers, 2004.

BAKER G. \& HACKER P. Wittgenstein: Understanding and Meaning. Volume 1 of an analytical commentary on the Philosophical Investigations, Part 1 - the essays. 2nd ed., extensively revised by P. Hacker. Oxford: Blackwell, 2005.

BLACK, M. A Companion to Wittgenstein's Tractatus. New York: Cambridge University Press, 1971.

BUDD, Malcolm. Wittgenstein's Philosophy of Psychology. 2a Edição. Padstow, Cornwall, Great Britain: Routledge London and New York, 1993.

ENGELMANN, M. L. Wittgenstein's Philosophical Development: Phenomenology, Grammar, the Genetic Method, and the Anthropological View. New York: Palgrave Macmillan, 2013.

FANN, K. T. Wittgenstein's Conception of Philosophy. University of California Press, Berkeley and Los Angeles, 1971. 
FREGE, G. Gottlob Frege: Briefe an Ludwig Wittgenstein. Grazer Philosophische Studien, 33/34, 18 GF-LW, de 28-6-19, p. 5-33, p. 19, 1989.

\section{GIL DE PAREJA, J. L. La Filosofia de la Psicología de Ludwig Wittgenstein.} Barcelona: PPU, 1992.

GILMORE, R. A. Philosophical health: Wittgenstein's method in "Philosophical investigations”. Lanham, MD: Lexington Books, 1999.

HACKER, P. Insight and Illusion: Themes in the Philosophy of Wittgenstein. Revised Edition. Oxford: Clarendon Press, 1986.

HACKER, P. Wittgenstein: Meaning and Mind. Oxford: Basil Blackwell, 1990.

HACKER, P. The Development of Wittgenstein's Philosophy of Psychology, 2010, p. 275-305. In: J. Cottingham \& P. Hacker (eds.). Mind, Method, and Morality: Essays in Honour of Anthony Kenny. Oxford/New York: Oxford University Press, 2010, p. 275-305.

HEBECHE, Luiz. O mundo da consciência: ensaio a partir da filosofia da psicologia de L. Wittgenstein. Porto Alegre: Edipucrs, 2002.

HILMY, S. The Later Wittgenstein: The emergence of a New Philosophical Method. Oxford: Basil Blackwell, 1987.

KARCZMARCZYK, P. Wittgenstein, Winch, Kripkenstein y la posibilidad de la crítica. Cuadernos de Filosofía. N. 30-31, 2012-2013, p. 7-37.

KENNY, A. 'Wittgenstein on the Nature of Philosophy'. In: A. Kenny (Ed.). The Legacy of Wittgenstein. Oxford: B. Blackwell, 1984.

KENNY, A. Wittgenstein. Oxford: Blackwell Publishing, 2006.

KING, J. \& LEE, D. (Ed. D. Lee) [LWL] Wittgenstein's lectures, Cambridge, 19301932, from the notes of John King and Desmond Lee. Chicago: University Chicago Press, 1980.

KRIPKE, S. Wittgenstein on Rules and Private Language - An elementary Exposition. Cambridge, MA: Harvard University Press, 1982.

LEAVIS, F. R.. Memories of Wittgenstein. In: R. Rhees, Ludwig Wittgenstein: Personal Recollections. Oxford: Blackwell, 1981.

MALCOLM, N. Ludwig Wittgenstein: a memoir. Oxford University Press, [1958]1984.

MARQUES, António. Vivência e significado. Introdução aos Últimos Escritos sobre a Filosofia da Psicologia de Wittgenstein. In: L. Wittgenstein. Últimos escritos sobre a Filosofia da Psicologia. Trad.: António Marques, Nuno Venturinha, João Tiago Proença. Lisboa: Fundação Calouste Gulbenkian, 2007. 
MILKOV, N. Wittgenstein's Method: The third phase of its development (1933-36), 2012. In: A. Marques. (Ed.). Knowledge, Language and Mind: Wittgenstein's Early Investigations: Wittgenstein's Thought in Progress. Berlin/New York: Walter de Gruyter, p. 80-94, 2012.

MOORE, G. E. Wittgenstein's Lectures in 1930-33, Part III. Mind, v. 253, p. 1-27, 1955.

MORENO, A. Como ler o álbum? In: A. Moreno, A. (Org.). Wittgenstein: como ler o álbum? Col. CLE, v. 55. Campinas: Unicamp, 2009.

RAMSEY, F. Critical Notices. Mind, 32, p. 465-478, 1923.

RHEES, R. Ludwig Wittgenstein: Personal Recollections. Oxford: Blackwell, 1981.

SCHULTE, Joachim. Experience and Expression: Wittgenstein's Philosophy of Psychology. Oxford: Clarendon Press, 1995.

SIQUEIRA, E. G. Como Ler o Álbum? Pela Composição de 'Vozes' que nele se deixam ouvir. In: A. Moreno, A. (Org.). Wittgenstein: como ler o álbum? Col. CLE, v. 55, p. 183-204. Campinas: Unicamp, 2009.

SMITH, P. J. Dos formas de escepticismo semántico. Theoria. Ciudad de México, v. 13, n.1, p. 101-118, 2002.

SOUZA, G. F. Wittgenstein e a tradição filosófica: aspectos metodológicos. Griot: Revista de Filosofia, 2017.

STERN, D. On Dialogues - Wittgenstein's Literary Style and Philosophical Methods. In: J. Drehmel; K. Jaspers (Eds.) Wittgenstein-Vorträge: Annäherungen aus Kunst und Wissenschaft [Wittgenstein Lectures: Approaches from Art and Science], p. 44-61. Hamburg: Junius Verlag, 2011.

STERN, D.; CITRON, G.; ROGERS, B. Moores's Notes on Wittgenstein's Lectures, Cambridge 1930-1933: Text, Context, and Content. (Nordic Wittgenstein Reviev - Preprintdaft), 2013.

STROLL, A. Moore and Wittgenstein On Certainty. Oxford: Oxford University Press, 1994.

WITTGENSTEIN, L. (MS/TS) = Wittgenstein's Nachlass: The Bergen Electronic Edition. Edited by The Wittgenstein Archives at the University of Bergen. Oxford: Oxford University Press, 2000.

WITTGENSTEIN, L. (TLP) = Tractatus Logico-Philosophicus. Transl. C.K. Ogden and F. P. Ramsey. London: Routledge, 2000.

WITTGENSTEIN, L. (LWL) = Wittgenstein's lectures, Cambridge, 1930-1932. Ed. KING, J.; LEE, H. D. P. (Ed.). Oxford: Basil Blackwell, 1980. 
WITTGENSTEIN, L. (MWL) = Wittgenstein's Lectures in 1930-33. In: MOORE, G. E. Part I, Mind, 63 (1954); Parte II, Mind, 63 (1954); Parte III, Mind, 64 (1955).

WITTGENSTEIN, L. (BB) = The blue (BB) und Brown Books (BrB). Oxford: Blakwell, 1992.

WITTGENSTEIN, L. (BT) = The Big Typescript. Ed. C. G. Luckhardt. Blackwell, Oxford, 2005.

WITTGENSTEIN, L. (Z) = Zettel. Ed. G.E.M. Ascombe \& G.H. von Wright. Transl. by G.E.M. Ascombe. Oxford: Basil Blackwell, 1967.

WITTGENSTEIN, L. $(\mathbf{P B})=$ Philosophical Remarks/Philosophische Bemerkungen . Ed. R. Rhees. Transl. by A. Kenny. Oxford: Basil Blackwell, 1974.

WITTGENSTEIN, L. (PU) = Philosophische Untersuchungen/Philosophical Investigations. Eds. von G.E.M. Anscombe and R. Rhees. Transl. G.E.M. Anscombe. Oxford: Basil Blackwell, 1968.

WITTGENSTEIN, L. (BPP I) = Remarks on the Philosophy of Psychology/ Bemerkungen über die Philosophie der Psychologie. Vol. 1.Ed. G.E.M. Anscombe and G.H. von Wright. Transl. G.E.M. Anscombe. Oxford: Basil Blackwell, 1980.

WITTGENSTEIN, L. (BPP II) =Remarkson the Philosophy of Psychology/

Bemerkungen über die Philosophie der Psychologie. Vol. 2.Ed. G.H. von Wright and Heikki Nyman.Transl. C.G. Luckhardt and Maximilian A.E. Aue. Oxford: Basil Blackwell, 1980.

WITTGENSTEIN, L. (LSPP I) = Last Writings on the Philosophy of Psychology/ Letzte Schriften über die Philosophie der Psychologie. Vol. 1.Ed. G.H. von Wright and Heikki Nyman.Transl. C.G. Luckhardt and Maximilian A. E. Aue. Oxford: Basil Blackwell, 1982.

WITTGENSTEIN, L. (LSPP II)= Last Writings on the Philosophy of Psychology/ Letzte Schriften über die Philosophie der Psychologie. Vol. 2.Ed. G.H. von Wright and Heikki Nyman.Transl. C.G. Luckhardt and Maximilian A. E. Aue. Oxford: Basil Blackwell, 1992.

WITTGENSTEIN, L. (ÜG) = Über Gewißheit/On Certainty. Ed. G.E.M. Anscombe and G.H. von Wright.Transl. Denis Paul and G.E.M. Anscombe. Oxford: Basil Blackwell, 1969.

Recebido: 14/01/2019

Aceito: 30/6/2019 